\title{
STUDI PERBANDINGAN PENCAMPURAN 4 JENIS LIMBAH YANG SULIT DIDAUR ULANG TERHADAP PENINGKATAN PROPERTI TANAH
}

\author{
Stanislaus $^{1}$ dan Aniek Prihatiningsih ${ }^{2}$ \\ ${ }^{1}$ Program Studi Sarjana Teknik Sipil, Universitas Tarumanagara, Jl.Letjen S. Parman No.1 Jakarta \\ Email: stanleymulyadi@yahoo.com \\ ${ }^{2}$ Program Studi Sarjana Teknik Sipil, Universitas Tarumanagara, Jl.Letjen S. Parman No.1 Jakarta \\ Email: aniekp@ft.untar.ac.id
}

\begin{abstract}
ABSTRAK
Keadaan tanah memiliki peran penting terhadap keperluan konstruksi dalam bidang teknik sipil, tanah berfungsi untuk menopang suatu bangunan konstruksi di atasnya, namun di beberapa tempat di Indonesia terdapat daerah yang memiliki tanah yang kurang baik seperti memiliki daya dukung rendah, hal ini sangat berpengaruh terhadap proses konstruksi. Selain tanah yang kurang baik limbah juga merupakan faktor permasalahan utama yang terjadi di Indonesia, limbah yang dibuang dan tertumpuk pada satu wilayah tertentu dapat menyebabkan dampak negatif terhadap lingkungan. Untuk menghindari hal tersebut maka dilakukanlah suatu penelitian agar limbah yang tidak dapat didaur ulang tersebut dapat digunakan sebagai bahan stabilisasi tanah, dan diharapkan dapat meningkatkan daya dukung dari tanah itu sendiri.Penelitian ini menggunakan tanah clay shale dari daerah Cietereup Sentul Bogor. Pengujian menggunakan unconfined compression test dengan komposisi variasi limbah yaitu serbuk kaca, abu sekam padi, styrofoam, dan fly ash type F sebesar $10 \%$ berdasarkan volume mold unconfined compression test.
\end{abstract}

Kata kunci: Unconfined Compression Test, Abu Sekam Padi, Serbuk Kaca, Clay Shale, Kuat Tekan Bebas.

\section{PENDAHULUAN}

Jumlah penduduk yang semakin meningkat setiap tahunnya membuat pembangunan infrastruktur dan konstruksi di Indonesia semakin bertambah, kebutuhan akan tempat tinggal dan aktifitas menyebabkan semakin banyak pembangunan konstruksi dan semakin banyak pula lahan yang diperlukan. Lahan untuk pembangunan fasilitas konstruksi mengakibatkan tidak dapat dihindari pembangunan di atas tanah yang memiliki kualitas kurang baik dalam bidang konstruksi seperti memiliki kekuatan dan daya dukung yang rendah. Salah satu contoh tanah yang memiliki kualitas kurang baik yaitu tanah clay shale.

Masalah limbah juga merupakan suatu masalah yang sangat serius dan menjadi salah satu masalah utama di Indonesia. Limbah yang dibuang dan tertumpuk pada satu wilayah tertentu dapat menyebabkan dampak negatif terhadap lingkungan.

Salah satu upaya untuk meningkatkan sifat tanah yang kurang baik tersebut adalah dengan stabilisasi tanah. Secara umum stabilisasi tanah merupakan suatu proses untuk memperbaiki sifat-sifat tanah dengan menambahkan sesuatu pada tanah tersebut, agar dapat menaikkan kekuatan tanah dan mempertahankan kekuatan geser. Tujuan dari stabilisasi tanah yaitu untuk mengikat dan menyatukan agregat material yang ada sehingga membentuk partikel yang lebih padat.

\section{Batasan Masalah}

-Sampel tanah yang digunakan merupakan tanah terganggu (disturbed).

-Variasi limbah yang digunakan yaitu serbuk kaca, dan abu sekam padi, styrofoam, dan fly ash.

-Nilai persentase variasi limbah terhadap tanah sebesar $10 \%$ berdasarkan volume mold.

-Pengujian dilakukan di laboratorium yaitu kuat tekan bebas Unconfined compression test

\section{Tujuan Penelitian}

-Mengetahui nilai $\mathrm{q}_{\mathrm{u}}$ setelah tanah dicampur dengan limbah.

-Mengetahui perbandingan $\mathrm{q}_{\mathrm{u}}$ setelah pencampuran dilakukan.

\section{TINJAUAN PUSTAKA}

\section{Tanah clay shale}


Tanah clay shale tersusun dari mineral-mineral lempung yang mempunyai karakter kembang susut yang besar apabila terjadi perubahan kadar air, karena adanya kandungan monmorillonite, illite, kaolinite, vermiculite, dan chrolite (Mitchell, 1976). Tanah clay shale memiliki perilaku yang sangat sensitif dengan perubahan cuaca sehingga dapat membuat tanah tersebut rentan dengan terjadinya longsor.

\section{Limbah Serbuk Kaca}

Limbah kaca sering kali ditemukan, misalnya pecahan botol, gelas, kaca, piring, dan sebagainya. Limbah kaca banyak dibuang ke tanah maupun sungai dan jumlah dibuangnya relatif banyak. Limbah yang dihasilkan oleh industri komersial bekas pemotongan dan penghalusan kaca cukup banyak setiap harinya. Jumlah limbah yang banyak berpotensi untuk mencemari alam karena kaca merupakan material yang sulit untuk diuraikan.

\section{Limbah Abu Sekam Padi}

Negara Indonesia merupakan negara penghasil padi terbesar. Panen gabah selain menghasilkan beras juga menghasilkan sekam padi. Pada saat dilakukan penggilingan bagian kulit pada padi akan terlepas dari butir beras, dan kulit tersebut merupakan limbah pada saat proses penggilingan. Limbah sekam padi tersebut bila dibakar akan menjadi abu sekam padi.

\section{Styrofoam}

Styrofoam atau bisa disebut dengan polistirena merupakan salah satu bahan yang sering digunakan untuk mengemas barang-barang yang mudah rusak dan juga makanan. Styrofoam tersebut menjadi daya tarik bagi para penjual selain harga belinya yang murah, praktis, mampu mencegah kebocoran, dan mempertahankan bentuknya saat dipegang, namun pemakaian styrofoam berbahaya bagi kesehatan manusia. Styrofoam merupakan bahan yang tidak bisa diurai secara alami bila styrofoam dibiarkan tanpa diolah dengan semestinya, maka limbah tersebut akan menjadi sumber pencemaran lingkungan yang merugikan masyarakat.

\section{Fly ash}

Fly ash merupakan limbah yang dihasilkan oleh industri yang menggunakan batubara (PLTU) dan berbentuk halus, bundar, dan bersifat pozolanik. Fly ash memiliki sifat sebagai pengisi pori (filler) yang berfungsi untuk mengisi rongga-rongga pada tanah sehingga rongga tersebut menjadi lebih rapat dan padat. Fly ash memiliki sifat pozolan yang terdiri dari unsur-unsur silikat yang tidak memiliki sifat perekat pada dirinya sendiri namun dengan butiran yang halus dapat bereaksi dengan air dan kapur membentuk bahan perekat.

Berdasarkan SNI S-15-1990-F pengklasifikasian fly ash dibagi menjadi tiga golongan yaitu tipe N, F, C yang didasarkan terhadap jumlah kandungan kalsium, silika, alumina, dan besi yang terkandung dalam fly ash tersebut.

-Kelas N

Buangan atau pozzolan alam terkalsinasi yang dipenuhi dengan kebutuhan yang memenuhi syarat yang dapat dipakai sesuai kelasnya, seperti beberapa tanah diatomaceous, opalinse chert dan serpihan-serpihan tuff dan debudebu vulkanik atau pumicities, dan bahan-bahan lainnya yang mungkin masih belum terproses oleh kalsinasi, dan berbagai material yang memerlukan kalsinasi untuk memperoleh sifat-sifat yang memuaskan, misalnya beberapa jenis tanah liat dan serpihan-serpihan.

-Kelas F

Abu batubara yang umumnya diproduksi dari pembakaran anthracite (batubara keras yang mengkilat) atau bitumenbitumen batubara yang memenuhi syarat - syarat yang dapat dipakai untuk kelas ini sperti yang disyaratkan. Abu batubara jenis ini memiliki sifat Pozzolanic.

-Kelas C

Abu batubara yang umumnya diproduksi dari lignite atau batubara subitumen yang memenuhi syarat yang dapat dipakai untuk kelas ini seperti yang disyaratkan. Abu batubara kelas ini, selain memiliki sifat pozzolan juga memiliki beberapa sifat yang lebih menyerupai semen. Untuk beberapa abu batubara kelas C biasa mengandung kapur lebih tinggi dari $10 \%$.

\section{Unconfined compression test}

Pengujian kuat tekan (unconfined compression test) adalah bentuk khusus dari pengujian yang dilakukan terhadap tanah lempung. Percobaan ini dilakukan dengan memberikan tegangan aksial secara berkala terhadap benda yang diuji sampai benda tersebut mengalami titik keruntuhan atau pada saat regangan aksial $(\varepsilon)$ mencapai 15 persen (ASTM D2166). Pengujian yang dilakukan untuk mendapatkan hasil kuat tekan tanah terhadap beban yang diterima. Percobaan ini menggunakan tanah yang lolos saringan no.10 dan ditambahkan dengan kadar air optimum sesuai data yang didapat pada percobaan compaction komposisi pencampuran limbah yang dilakukan adalah sebesar $10 \%$ dari volume mold unconfined compression test yang berada di laboratorium. 
Tegangan aksial $(\sigma)$

$$
\sigma=\frac{\mathrm{P}}{\boldsymbol{A}}
$$

$\mathrm{P}=$ beban yang bekerja

$\mathrm{A}=$ luas penampang tanah

Regangan aksial $(\varepsilon)$

$$
\varepsilon=\frac{\Delta \mathrm{I}}{1 . \mathrm{x}} \times 100 \%
$$

Keterangan

$\Delta \mathrm{L}=$ perubahan panjang benda uji

\section{METODOLOGI PENELITIAN}

\section{Pengambilan Data}

Sampel tanah yang diuji adalah tanah clay shale yang diambil berada di Jl. Babakan Sirkuit Tangkil, Citereup, Bogor, Indonesia dengan kedalaman 6-10 m. Sampel tanah diambil pada tanggal 4 Maret 2019. Tanah yang digunakan bersifat terganggu (disturbed).

\section{Metode Pengujian Laboratorium}

-Water Content ASTM

-Specific Gravity Test

-Atterberg Limits

-Grain Size

-Compaction

-Unconfined Compression Test

\section{PENGOLAHAN DATA}

Pengolahan data yang dilakukan berdasarkan hasil yang didapat dari pengujian laboratorium yaitu water content, specific gravity, atterberg limits, grain size, compaction, unconfined compression test untuk mengetahui karakteristik dan kuat tekan dari sampel tanah yang akan digunakan.

\section{Pengujian Water Content}

Tabel 1. Hasil Uji Water Content

\begin{tabular}{ccccc}
\hline Keterangan & Sampel 1 & Sampel 2 & Sampel 3 & Sampel 4 \\
\hline Water content \% & 14.9 & 16.9 & 14.9 & 9.8 \\
Rata-rata & & \multicolumn{2}{c}{14.2} & \\
& & & \\
\hline
\end{tabular}

\section{Pengujian Specific Gravity}

Tabel 2. Hasil uji Specific Gravity

\begin{tabular}{ccccc}
\hline Keterangan & Sampel 1 & Sampel 2 & Sampel 3 & Sampel 4 \\
\hline Gs $\left(20^{\circ} \mathrm{C}\right)$ & 2.75 & 2.82 & 2.70 & 2.70 \\
Rata-rata & & & 2.75 \\
\end{tabular}




\section{Pengujian Atterberg Limits}

Dari pengujian atterberg limits didapatkan hasil bahwa jenis tanah yang diuji merupakan tanah ML yaitu lanau anorganik (silt inorganik).

Tabel 3. Hasil Uji Atterberg Limits

\begin{tabular}{cccccc}
\hline Keterangan & Sampel 1 & Sampel 2 & Sampel 3 & Sampel 4 & Rata-rata \\
\hline Liquid limit & 33.5 & 34.2 & 33.2 & 34.0 & 33.8 \\
Plastic Limit & 25.5 & 26.8 & 26.4 & 27.5 & 26.6 \\
Plasticity Index & 8.0 & 7.4 & 6.8 & 6.5 & 7.2 \\
\hline
\end{tabular}

\section{Pengujian Grain Size}

Tabel 4. Hasil Uji Grain Size

\begin{tabular}{cccccc}
\hline $\begin{array}{c}\text { Jenis } \\
\text { butiran }\end{array}$ & Sampel 1 & Sampel 2 & Sampel 3 & Sampel 4 & Rata-rata \\
\hline Gravel(\%) & 0.00 & 0.00 & 0.00 & 0.00 & 0.00 \\
Sand(\%) & 1.66 & 1.77 & 1.76 & 1.77 & 1.74 \\
Silt (\%) & 85.69 & 87.54 & 89.50 & 77.82 & 85.13 \\
Clay (\%) & 12.65 & 10.69 & 8.75 & 20.41 & 13.13 \\
\hline
\end{tabular}

\section{Hasil Compaction}

pengujian compaction yang dilakukan diperoleh hasil kepadatan kering sebesar $18.2 \mathrm{kN} / \mathrm{m}^{3}$ dan kadar air optimum yang didapat sebesar $16 \%$.

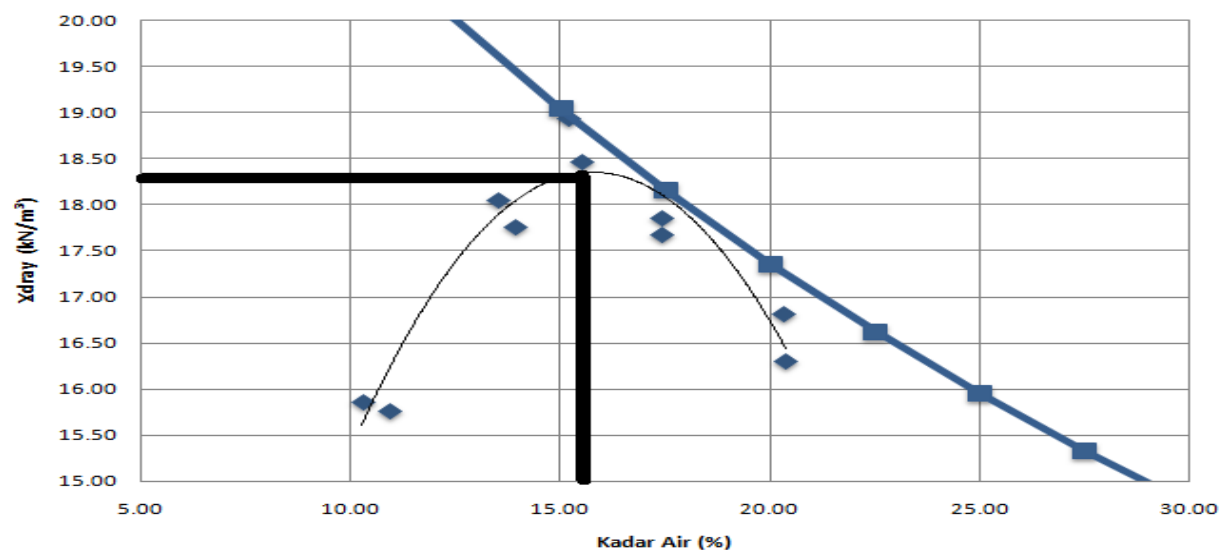

Gambar 1. Pengujian Compaction 


\section{Hasil Pengujian Unconfined Compression Test Sampel Tanah Clay shale tanpa campuran limbah}

Tabel 5. Nilai quu Sampel Clay Shale tanpa campuran limbah

\begin{tabular}{cccccc}
\hline Keterangan & Sampel 1 & Sampel 2 & Sampel 3 & Sampel 4 & Rata-rata \\
\hline$q_{u u}\left(\mathrm{kN} / \mathrm{m}^{2}\right)$ & 356.85 & 433.67 & 333.95 & 356.27 & 370.19 \\
\hline
\end{tabular}

Dari pengujian UCT yang dilakukan di laboratorium untuk tanah clay shale tanpa menggunakan campuran limbah didapatkan hasil quu dari sampel 1 sebesar $356.85 \mathrm{kN} / \mathrm{m}^{2}$, sampel 2 sebesar $433.63 \mathrm{kN} / \mathrm{m}^{2}$, sampel 3 sebesar 333.95 $\mathrm{kN} / \mathrm{m}^{2}$, dan sampel 4 sebesar $356.27 \mathrm{kN} / \mathrm{m}^{2}$. Sehingga didapatkan nilai rata-rata dari keempat sampel tersebut sebesar $370.19 \mathrm{kN} / \mathrm{m}^{2}$.

\section{Hasil Pengujian Unconfined Compression Test Sampel Campuran Tanah Clay shale dan Serbuk Kaca}

Tabel 6. Nilai quu Sampel Clay Shale dan Serbuk Kaca

\begin{tabular}{cccccc}
\hline Keterangan & Sampel 1 & Sampel 2 & Sampel 3 & Sampel 4 & Rata-rata \\
\hline$q_{u u}\left(\mathrm{kN} / \mathrm{m}^{2}\right)$ & 541.99 & 546.16 & 540.16 & 519.85 & 537.04 \\
\hline
\end{tabular}

Hasil pengujian UCT yang dilakukan di laboratorium untuk campuran serbuk kaca didapatkan hasil quu dari sampel 1 sebesar $541.99 \mathrm{kN} / \mathrm{m}^{2}$, sampel 2 sebesar $546.16 \mathrm{kN} / \mathrm{m}^{2}$, sampel 3 sebesar $540.16 \mathrm{kN} / \mathrm{m}^{2}$, dan sampel 4 sebesar $519.85 \mathrm{kN} / \mathrm{m}^{2}$. Sehingga didapatkan nilai rata-rata dari keempat sampel tersebut sebesar $537.04 \mathrm{kN} / \mathrm{m}^{2}$.

\section{Hasil Pengujian Unconfined Compression Test Sampel Campuran Tanah Clay shale dan Abu Sekam Padi}

Tabel 7. Nilai quu Sampel Clay Shale dan Abu Sekam Padi

\begin{tabular}{cccccc}
\hline Keterangan & Sampel 1 & Sampel 2 & Sampel 3 & Sampel 4 & Rata-rata \\
\hline$q_{u u}\left(\mathrm{kN} / \mathrm{m}^{2}\right)$ & 410.2 & 397.65 & 386.7 & 402.38 & 399.24 \\
\hline
\end{tabular}

Pengujian UCT yang dilakukan di laboratorium untuk campuran abu sekam padi diperoleh hasil quu dari sampel 1 sebesar $410.2 \mathrm{kN} / \mathrm{m}^{2}$, sampel 2 sebesar $397.65 \mathrm{kN} / \mathrm{m}^{2}$, sampel 3 sebesar $386.7 \mathrm{kN} / \mathrm{m}^{2}$, dan sampel 4 sebesar 402.38 $\mathrm{kN} / \mathrm{m}^{2}$. Sehingga didapatkan nilai rata-rata dari keempat sampel tersebut sebesar $399.24 \mathrm{kN} / \mathrm{m}^{2}$.

Hasil Pengujian Unconfined Compression Test Sampel Campuran Tanah Clay shale dan styrofoam

Tabel 8. Nilai quu Sampel Clay Shale dan styrofoam

\begin{tabular}{cccccc}
\hline Keterangan & Sampel 1 & Sampel 2 & Sampel 3 & Sampel 4 & Rata-rata \\
\hline$q_{u u}\left(\mathrm{kN} / \mathrm{m}^{2}\right)$ & 428.43 & 425.75 & 444.89 & 427.34 & 431.61 \\
\hline
\end{tabular}

Pengujian UCT yang dilakukan di laboratorium untuk campuran styrofoam diperoleh hasil quu dari sampel 1 sebesar $428.43 \mathrm{kN} / \mathrm{m}^{2}$, sampel 2 sebesar $425.75 \mathrm{kN} / \mathrm{m}^{2}$, sampel 3 sebesar $444.34 \mathrm{kN} / \mathrm{m}^{2}$, dan sampel 4 sebesar 427.34 $\mathrm{kN} / \mathrm{m}^{2}$. Sehingga didapatkan nilai rata-rata dari keempat sampel tersebut sebesar $431.61 \mathrm{kN} / \mathrm{m}^{2}$. 


\section{Hasil Pengujian Unconfined Compression Test Sampel Campuran Tanah Clay shale dan fly ash}

Tabel 9. Nilai quu Sampel Clay Shale dan fly ash

\begin{tabular}{cccccc}
\hline Keterangan & Sampel 1 & Sampel 2 & Sampel 3 & Sampel 4 & Rata-rata \\
\hline$q_{u u}\left(\mathrm{kN} / \mathrm{m}^{2}\right)$ & 500.61 & 474.46 & 491.97 & 498.11 & 491.22 \\
\hline
\end{tabular}

Hasil pengujian UCT yang dilakukan di laboratorium untuk campuran fly ash didapatkan hasil quu dari sampel 1 sebesar $500.61 \mathrm{kN} / \mathrm{m}^{2}$, sampel 2 sebesar $474.46 \mathrm{kN} / \mathrm{m}^{2}$, sampel 3 sebesar $491.97 \mathrm{kN} / \mathrm{m}^{2}$, dan sampel 4 sebesar $498.11 \mathrm{kN} / \mathrm{m}^{2}$. Sehingga didapatkan nilai rata-rata dari keempat sampel tersebut sebesar $491.22 \mathrm{kN} / \mathrm{m}^{2}$.

Tabel 10. Persentase Peningkatan Kekuatan Nilai quu

\begin{tabular}{cccccc}
\hline Koterangan & \multicolumn{5}{c}{ Tanah clay shale } \\
\cline { 2 - 5 } & Tanpa limbah & Serbuk kaca & Abu sekam padi & styrofoam & Fly ash \\
\hline $\begin{array}{c}q_{\text {un. }} \text { Rata-rata } \\
\left(\mathrm{kN} / \mathrm{m}^{2}\right)\end{array}$ & 370.19 & 537.04 & 399.24 & 431.61 & 491.22 \\
$\begin{array}{c}\text { Perbandingan } \\
\text { kekuatan (\%) }\end{array}$ & 0 & 45.1 & 7.9 & 16.6 & 32.7 \\
\hline
\end{tabular}

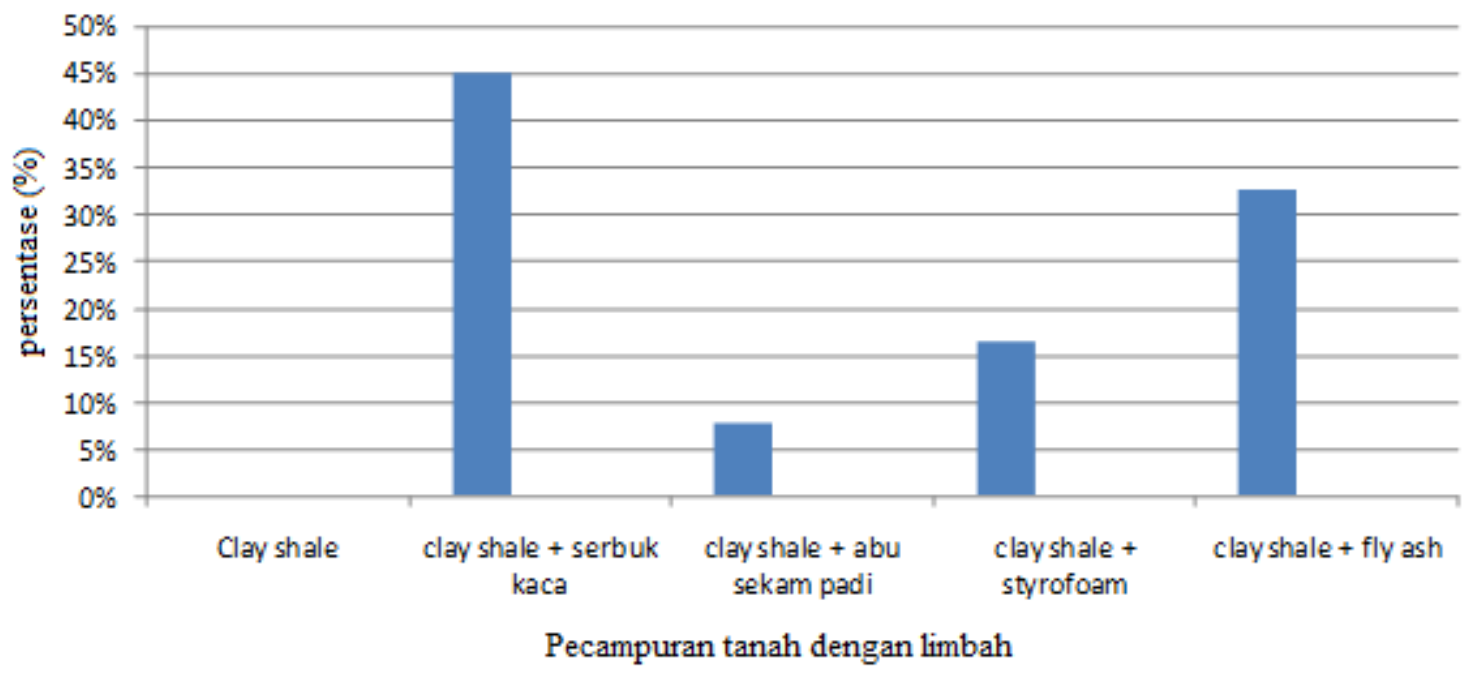

Gambar 2. Grafik persen perbandingan pencampuran limbah

Perbandingan nilai $\mathrm{q}_{\mathrm{uu}}$ rata-rata yang didapat dari pengujian unconfined compression test diperoleh hasil bahwa pencampuran tanah clay shale dengan limbah serbuk kaca sebanyak $10 \%$ volume mold unconfined compression test mengalami kenaikan nilai kuat tekan terhadap kekuatan dari tanah clay shale itu sendiri sebesar $45.1 \%$, limbah fly ash sebesar 32.7\%, dan limbah styrofoam sebesar 16.6\%. Sedangkan pencampuran tanah clay shale dengan limbah abu sekam padi dengan komposisi yang sama mengalami kenaikan pula sebesar 7.9\%. Dapat disimpulkan bahwa penambahan limbah sebesar $10 \%$ dapat meningkatan kekuatan terhadap tanah clay shale itu sendiri. 


\section{KESIMPULAN}

Tanah clay shale dari lokasi Jl. Babakan Sirkuit Tangkil, Citereup, Bogor, Indonesia dengan kedalaman 6-10 m setelah dicampur dengan 10\% dari volume mold uji unconfined compression test (UCT) dan dilakukan pengujian uji desak bebas mengalami peningkatan. Untuk tanah dengan campuran limbah serbuk kaca mengalami peningkatan kuat tekan tertinggi sebesar $45.1 \%$ dan pencampuran dengan limbah abu sekam padi juga mengalami peningkatan terendah dibandingkan limbah lainnya sebesar 7.9\% dari tanah clay shale yang tidak diberikan campuran limbah Penambahan limbah yang berfungsi sebagai filler dapat mengikat antar partikel, dan mengisi rongga pada partikel tanah sehingga rongga tersebut menjadi lebih padat dan menghasilkan kuat tekan pada sampel tanah menjadi lebih tinggi.

\section{DAFTAR PUSTAKA}

ASTM D2166. 2014. Standart Test for Unconfined Compressive Strength of Cohesive Soil. United States: American Society for Testing and Materials.

ASTM D2487-10. 2014. Standard Practice for Classificattion of Soils for Engineering Purposes (Unified Soil Classification System). United States: American Society for Testing and Materials.

Mitchell, J.K. 1976.“Fundamentals of Soil Behavior”, John Wiley \& Sons, Inc., New York. 
